OPEN ACCESS

Edited by:

Eva M. Romera,

University of Cordoba, Spain

Reviewed by:

Daniel Falla

University of Cordoba, Spain

Erik A. Ruzek,

NWEA, United States

*Correspondence:

Marloes M. H. G. Hendrickx m.m.h.g.hendrickx@tue.n

Specialty section:

This article was submitted to

Educational Psychology,

a section of the journal

Frontiers in Education

Received: 02 June 2020 Accepted: 14 September 2020 Published: 20 October 2020

Citation:

Hendrickx MMHG, Mainhard T, Cillessen AHN and Brekelmans $M$ (2020) Teacher Behavior With Upper Elementary School Students in the Social Margins of Their Classroom Peer Group. Front. Educ. 5:568849. doi: 10.3389/feduc.2020.568849

\section{Teacher Behavior With Upper Elementary School Students in the Social Margins of Their Classroom Peer Group}

\author{
Marloes M. H. G. Hendrickx ${ }^{1,2 \star}$, Tim Mainhard ${ }^{1}$, Antonius H. N. Cillessen ${ }^{3}$ and \\ Mieke Brekelmans ${ }^{1}$ \\ ${ }^{1}$ Department of Education, Utrecht University, Utrecht, Netherlands, ${ }^{2}$ Eindhoven School of Education, Eindhoven University \\ of Technology, Eindhoven, Netherlands, ${ }^{3}$ Behavioural Science Institute, Radboud University, Nijmegen, Netherlands
}

Students in the social margins of their classroom peer group, in the current study operationalized as students who are often by themselves, do not belong to a group of friends, and are unpopular, are hampered in their social development. In line with social referencing, which states that teachers can affect peer perceptions through their interactions with students, we hypothesized that teachers may contribute to the social participation and integration of these students, by modeling frequent and positive interaction with them. We therefore explored teacher behavior with socially marginalized students, and how these interactions were related to changes in the severity of their social marginality over time. Multilevel analyses were performed with a sample of Dutch 824 fifth-grade students $\left(M_{\text {age }}=10.63\right)$ and their 32 teachers. Teachers had less frequent interactions with students in the social margins of the group, particularly when these students were unpopular. Nonetheless, we found some evidence for a social referencing mechanism: latent growth modeling showed that when teachers acted less negatively toward socially marginalized as well as rejected students, they became more socially integrated in their peer-group over time.

Keywords: peer relations, teacher behavior, teacher-student relationships, social referencing, teacher practices

\section{INTRODUCTION}

Students in the margins of their classroom's peer group are loosely connected to their classmates and rarely engage in peer interactions (Rubin et al., 2009; Spangler and Gazelle, 2009). However, being socially engaged with peers is important for students to develop social skills (Rubin et al., 2009), and provides opportunities for collaborative learning activities, boosting academic skills (Wentzel, 2005). Socially marginal students are at risk of developing internalizing and externalizing behavioral problems (Gazelle and Ladd, 2003; Laursen et al., 2007) and are often the target of teasing and bullying, which in turn is related to a limited sense of belonging (Wormington et al., 2016) and to academic difficulties (Lee and Cornell, 2009).

Research has shown how student characteristics (e.g., temperament, biology; Henderson et al., 2001; Hariri et al., 2002), peer group characteristics (e.g., group size, status hierarchy; Bukowski and Véronneau, 2014), and family characteristics (e.g., overprotective parenting; Coplan et al., 2008) contribute to social marginalization in classroom peer groups. In addition, teachers, as the single 
professionals close to the classroom peer society yet just not part of it, have the unique opportunity to manage classroom peer interactions and relationships (Farmer et al., 2011). Through their interactions with students, teachers affect students' peer relatedness, as shown by several studies focusing on acceptance, rejection, or popularity (Hughes et al., 2001; McAuliffe et al., 2009; De Laet et al., 2014; Hendrickx et al., 2017b). Teachers thus seem to have the potential to positively affect the social integration of socially marginal students. Because of the potentially detrimental effects on developmental outcomes, it is essential for teachers to understand how they can increase the social participation of marginal students, as part of their professional role. To increase the current knowledge regarding teacher effects, the current study explored how teachers interact with students in the social margins of their classroom peer group and examined how these interactions are related to changes in this disadvantageous position over time.

\section{The Social Margins of the Classroom Peer Group}

The concept of social marginalization has received substantial attention in developmental psychology (e.g., Rubin et al., 2009), social psychology (e.g., Ellemers and Jetten, 2013), and social network studies (e.g., Borgatti et al., 2013) and has multiple definitions and conceptualizations. In developmental psychology, being marginal in the peer group is often seen from an individual perspective, with a focus on social isolation and its antecedents and consequences (Rubin et al., 2009). Students who are isolated are those who are often by themselves and rarely engage in interactions with peers (Spangler and Gazelle, 2009). In social psychology, marginalization tends to be approached from what it conceptually means to belong to a group and how individuals become group members. By definition, marginal group members behave less similar to others, are more disengaged, and have limited social impact in the group (Ellemers and Jetten, 2013). Social network theorists have a more technical approach and use the term "periphery" to indicate those regions of the social network were members are only loosely connected to others. Individuals who are peripheral have none or few ties to the more densely connected core of their social network (Borgatti et al., 2013).

In sum, occupying a socially marginal position in the classroom peer group is not a unidimensional phenomenon with a single manifestation, but a multifaceted construct (Coplan and Rubin, 2010; Ellemers and Jetten, 2013; Bukowski and Véronneau, 2014). Therefore, we focused on three facets of social marginalization: often being by oneself (solitude), not belonging to friendship groups, and being unpopular. Popularity as a construct can be distinguished from likeability to indicate a student's social status in their peer group (Van den Berg et al., 2020). Unpopular students can be considered to have limited social impact [see Ellemers and Jetten (2013)].

In peer nomination research, social marginality is often operationalized as not being selected on a certain item, for instance for friendship or popularity. However, not being selected for a characteristic does not carry information about the relationship between the classmate and the target student (Cillessen and Marks, 2017). Operationalizing social marginalization as not being selected makes it difficult to examine the degree to which a student does not belong to the peer group. Therefore, in this study we used active nominations for students as being alone often, not belonging to a group of friends, and being unpopular.

\section{Mechanisms Underlying Social Marginalization}

Both in social and developmental psychology, multiple pathways of social marginalization have been identified. Rubin (1982) was one of the first to distinguish being excluded (i.e., being ignored or neglected by peers) from social withdrawal (i.e., choosing not to engage with peers). Similarly, Ellemers and Jetten (2013) described how social marginalization can result from low inclusion goals by the group (the group does not wish to include the individual) or the individual (the individual does not wish to be part of the group). Students who want to be included but are faced with a group that moves away from them are considered excluded (Coplan and Rubin, 2010) or rejected marginal students (Ellemers and Jetten, 2013). When peers exclude a student, this is considered a behavioral manifestation of peers' negative affective reaction to the student (Rubin et al., 2015). In the current study this mechanism is tapped by including peer rejection. Peer rejection refers to the degree to which students are disliked by their peers, and is associated with aggressive behavior (Asher and McDonald, 2009). Peer rejection and social marginalization are two different constructs, as some students who are rejected by many peers may have a tightly connected group of close friends. Students who have low personal inclusion goals and choose not to participate in peer interaction can be considered withdrawn (Spangler and Gazelle, 2009) or independent marginal (Ellemers and Jetten, 2013). Although these students are comfortable in their social position, they too are at risk of sub-optimal adjustment and development, because their limited engagement with peers prevents them from expanding their skills (Coplan and Armer, 2007; Nelson, 2013).

\section{The Role of the Teacher}

A growing research base is focusing on teachers' invisible hand (Farmer et al., 2011), that is, teachers' potentially large impact on classroom peer relationships. Teacher practices are related to many peer experiences, including, at the individual level, peer acceptance (Kiuru et al., 2015; Hughes and Im, 2016; Hendrickx et al., 2017b) and popularity (Moore et al., 2012; De Laet et al., 2014), and at the classroom level relationship hierarchy and behavioral norms (Gest and Rodkin, 2011; Hendrickx et al., 2016). In this section we address how research findings on the teacher as a social referent may help us understand their possible impact on students in the social margins of the classroom peer group.

\section{The Teacher as a Social Referent}

Hughes et al. (2001) argued that teachers' interactions with their students provide classmates with cues that can be used as a model for their own interactions with each other [see also Hughes et al. (2014)]. Thus, teachers are a social referent, modeling 
perceptions of and interactions with students (Hughes et al., 2001, 2014). Indeed, teacher behavior with a student is associated with students' peer acceptance or rejection in the classroom (White and Kistner, 1992; McAuliffe et al., 2009; Hendrickx et al., 2017b). In this line of reasoning, teacher behavior impacts students' peer status through classmates' perceptions of teacher behavior [see Hughes et al. (2014)]. Accordingly, peers' perceptions of positive versus negative teacher behavior have been associated with peer acceptance as well (Hughes et al., 2001, 2014; Hendrickx et al., 2017b).

\section{Social Referencing and Social Marginality}

Translating this social referencing mechanism to social marginalization, teachers may improve social participation by interacting frequently with a student (modeling interaction in itself) and by having positive instead of negative interactions (modeling positive interaction). Modeling positive behavior with a student may be especially effective for students in the social margins of the group who are viewed negatively by their peers (i.e., rejected). However, existing research, albeit limited and mostly undertaken in preschool or first-grade settings, suggests that this is not typical teacher behavior with marginal students. Teachers have reported (Evans, 2001) and have been observed (Rudasill and Rimm-Kaufman, 2009) to have less rather than more frequent interactions with socially marginalized students. These studies have argued that because these students have limited social participation, they also infrequently trigger their teacher's attention. In contrast, other studies suggested that teachers do actively engage with socially marginalized students (Coplan and Prakash, 2003; Thijs et al., 2006). Regarding valence of interaction, teachers reported to have more negative and conflicted relationships with first-grade students whom they perceived to be relative outsiders (Rudasill and Rimm-Kaufman, 2009; Arbeau et al., 2010). Thus, there is some evidence that with young students, teachers generally behave in accordance with the relatively marginal social status of students.

\section{Present Study}

Students in the social margins of their classroom peer group are at risk of adjustment problems. It is important to understand how teacher behavior is associated with their social position in the classroom to ultimately be able to help teachers to support these students. We examined the socially marginal position of a child in two ways, first by creating a compound score combining solitude, not belonging to a group, and being unpopular, indicating a general socially marginal position, and second by assessing effects per facet of social marginality separately. The first strategy allows a more holistic view on the processes investigated in the current study. Moreover, combining multiple items has statistical advantages. Looking at the three facets of social marginality separately allows to investigate how teacher behavior might have differential effects on each of these facets.

The first goal of this study was to explore the frequency and valence of teacher behavior with socially marginalized students as compared to other students: How frequently and with what valence do teachers behave in everyday interaction with socially marginalized students? To answer this question, we first compared teacher behavior with socially marginalized students to teacher behavior with other students, based on classroom observations. To triangulate these observations and in line with social referencing theory (Hughes et al., 2001, 2014), we measured peers' perceptions of the frequency and valence of teacher behavior toward a student. Next, to do justice to the mechanisms of becoming socially marginalized [see Bukowski and Véronneau (2014), Ellemers and Jetten (2013)], we examined whether teacher behavior was different when students were more or less strongly rejected by peers, or when students themselves had a lower or higher social inclusion goal. Based on earlier studies with younger students (Evans, 2001; Rudasill and RimmKaufman, 2009), we expected that, on average, teachers would interact less frequently with socially marginalized students than with other students. Moreover, we expected teachers to show less positive behavior with these students [see Arbeau et al. (2010)], especially if they were also rejected by their peers (De Laet et al., 2014).

The second goal was to examine social marginalization developmentally and see whether teacher behavior might help students in the social margins of their classroom peer group to become more socially engaged over time: How does teacher behavior with socially marginalized students relate to change in these student' social position over time? Based on studies that indicated the effectiveness of teacher social referencing for peer acceptance (Hughes et al., 2001, 2014; Hendrickx et al., 2017b), we expected that students with whom the teacher interacted more frequently would become more socially engaged (i.e., less alone, belonging to a peer group, and more popular) over time, because the teacher would model interacting with them to classroom peers. We expected similar effects for students with whom the teacher had relatively more positive interactions. Positive interaction was expected to be particularly effective for those socially marginal students who were also rejected by their peers, because of its contrasting nature compared to classmates' negative affective evaluations (Rubin et al., 2015).

\section{METHOD}

\section{Participants}

Students and their teachers from 32 fifth-grade classrooms ${ }^{1}$ from 22 elementary schools in the Netherlands participated in three waves of data collection (T1-T3). All students who participated had parental consent to complete questionnaires and to be recorded on camera ( 824 out of $849 ; 97.1 \%$ ). Due to absence on the day of data collection or not being part of the class yet/anymore, 797 students participated at T1, 787 at T2, and 789 at T3. Students' mean age at T1 was 10.63 years $(S D=0.49$, range $=8.60-12.79) ; 48.5 \%$ were girls. Of the students, $85.7 \%$ were Dutch (both parents born in the Netherlands), $6.5 \%$ had

\footnotetext{
${ }^{1}$ In total, 59 classes participated in the research project, which involved a quasiexperimental study in which teachers were asked to adapt their behavior with certain students. The current results are based on the 33 control classes, because the aim was to examine naturally occurring teacher behavior. One classroom dropped out of the project after T1 and was therefore excluded from the current study.
} 
other Western backgrounds (at least one parent born in another Western country), and $7.8 \%$ had a non-Western background (at least one parent born in a non-Western country). This distribution was representative for the areas in which the schools were located (Statistics Netherlands, 2012). Average class size was 26.34 students $(S D=3.55$, range $18-32)$. As is common in the Netherlands, in 27 (84.4\%) of the classrooms in our sample the composition of the group was largely the same as the year before, with only a few students who had moved in or out.

Dutch primary schools cover eight years, from kindergarten (age 4) to sixth grade (age 12). When moving on to the next grade, students generally stay together as a classroom group, but do have a new teacher Teachers' mean age was 43.23 years $(S D=12.95$, range $25.75-62.47)$; their average experience was 17.03 years $(S D=12.26$, range $3-39)$. All teachers were Dutch and 20 were female $(62.5 \%)$. Due to a personal leave of the participating classroom teacher because of travel or maternity leave, one substitute teacher was present at $\mathrm{T} 2$ and one at $\mathrm{T} 3$. The teacher data of these classrooms at those measurement moments were discarded.

\section{Measures}

The majority of our measures were peer nomination items. For each item, primary participants (those present and consented) were asked to nominate which classmates best fitted the description (e.g., who are your friends?) from a list of classmates' first names. Both same- and cross-sex nominations were allowed, and nominations were unlimited. Nominations of non-consented students were excluded from the dataset, but students could nominate their absent classmates. To avoid sequence effects [see Poulin and Dishion (2008)], classmates' names were presented in a random order that was different for each participant.

\section{Social Marginality in the Peer Group}

The degree to which students were considered to be socially marginalized was measured using three peer nomination indicators: solitude ("which of your classmates are often by themselves during breaks?"), not belonging to a group ("which of your classmates do not belong to a group of friends?") and unpopularity ("which of your classmates are least popular?"). For each item, proportion scores were computed as the total number of nominations received divided by the maximum number of possible nominations. Proportion scores were group mean centered to account for class-level tendencies to nominate more or fewer students.

These indicators were analyzed as such, but also combined into a general social marginality score. Cronbach's alpha over the three proportion scores was $0.83,0.81$, and 0.80 at the three measurement waves. Proportion scores for unpopularity were larger than those for solitude and not belonging to a group. To achieve an equal scaling of the three indicator variables in the compound social marginality score, each of these group mean centered scores was within each occasion standardized over the sample and finally averaged to form the compound score for each occasion.

\section{Socially marginal subsamples}

As might be expected, the social marginality measure as well as the three indicators were strongly skewed. That is, $80 \%$ of the students were nominated by hardly any peer on each of the three indicators. Therefore, we created subsamples: socially marginal and non-marginal subsamples for the compound score as well as subsamples for each indicator.

The students with the $20 \%$ highest scores at $\mathrm{T} 1$ were considered (relatively) socially marginal, and the remaining $80 \%$ were considered non-marginal. The cut-off of $20 \%$ was chosen in accordance with the three-tier model based on Positive Behavioral Interventions and Supports (PBIS; Reinke et al., 2009). According to this model, $80 \%$ of students respond successfully to proactive universal (classroom) strategies, but the top 20\% will experience social problems and will not respond to such universal school-wide interventions and will need more intensive interventions to help them succeed in school.

The subsample of socially marginal students in our sample at $\mathrm{T} 1$, based on the compound score, consisted of on average 5.11 students per class $(S D=1.74)$. We compared the demographics of non-marginal students with those who were considered to be in the social margins of their classroom peer group on at least one measurement occasion $(n=212)$. This group did not differ statistically from the other students in age, $t(817)=-0.17, p$ $=.862$, gender distribution, $\chi^{2}(1)=0.21, p=.650$, or parents' country of birth, $\chi^{2}(2)=2.17, p=.337$.

\section{Peer Rejection and Inclusion Goals}

To do justice to the multiple ways in which students can become socially marginalized, we measured: (a) the extent to which students were rejected by peers, and (b) students' desire for (more) social interaction (i.e., high vs. low inclusion goals).

\section{Peer rejection}

Using the same peer nomination procedure as described above, students were asked to indicate which of their classmates they liked least. Peer rejection scores were calculated for each student as the proportion of the available classmates that had nominated them.

\section{Inclusion goals}

To measure students' inclusion goals, we included the negative aspect of the social self-concept scale as adapted from the Dutch version of the Harter scales (Veerman et al., 2004). Three selfreport items were included (e.g., "I would like to have more friends"), which were answered on a scale ranging from 1 (not true at all) to 5 (completely true). Cronbach's alpha at T1-3 was $0.71,0.72$, and 0.74 .

\section{Teacher behavior}

Teacher behavior with a student was measured from an outside observer's perspective and from the peer perspective.

\section{Observed teacher behavior}

Teacher behavior was coded from $2 \mathrm{~h}$ of video observation in each classroom at each wave. Event sampling was used to select teacher comments that were (a) expressed in connection with a single student (dyadic) or a small group, and (b) expressed 
in public, that is, when at least half the students were present in a whole-class teaching setting [see McAuliffe et al. (2009)]. Teacher behavior was coded as positive, negative, or neutral in the cognitive and affective domain. Teacher behavior in the cognitive domain referred to how the teacher evaluated a student's academic contributions (e.g., stating that an answer was correct vs. incorrect). The affective domain referred to how the teacher evaluated a student as a person or a student's behavior (e.g., praising a student for being quiet vs. asking a student not to speak during instruction). Teacher behavior was coded as neutral when it did not contain a specific affective or cognitive valence. Each teacher comment was independently coded in both domains. Frequency of teacher behavior with each student was computed as the total number of teacher behaviors directed to the student. The valence of teacher behavior in each domain was computed as the difference between the proportions of positive and negative comments in that domain, scaled from -1 to +1 . For more information on the coding system of teacher behavior, including further examples, see Author et al. (2016).

After developing the coding system for teacher behavior, the first author and two research assistants tested it for interobserver reliability. First, agreement for event occurrence ranged from 81 to $87 \%$ for the pairs of observers. Second, a set of 1,624 occurrences ( $5.8 \%$ of the total body) of teacher behavior was coded with respect to content. For the pairs of observers, weighted Cohen's kappa ranged from 0.72 to 0.77 for the affective domain (substantial agreement; Landis and Koch, 1977) and from 0.83 to 0.86 for the cognitive domain (almost perfect agreement). After establishing the coding scheme as a reliable measure, three additional research assistants were trained to code the video data until they reached agreement with the first author of at least $80 \%$ for event occurrence and a weighted Cohen's kappa of at least 0.80 for both the affective and cognitive domains.

\section{Peer-perceived teacher behavior}

Three peer nomination items were used to measure peerperceived teacher behavior. For the frequency of teacher-student interactions, students were asked to nominate classmates "who hardly receive any attention from Mrs./Mr. (teacher name)." The proportion score of this item was subtracted from 1 , so that a higher score indicated more frequent interaction with the teacher. For the valence of teacher-student interactions, students were asked to nominate classmates who "receive a lot of praise and compliments" (positive) and "at which the teacher gets angry often" (negative). Items again contained the name of the teacher. The valence score was created by computing the difference between the positive and negative proportion scores (range $-1-+1$ ).

\section{Procedure}

Randomly selected elementary schools in the middle, south, and east of the Netherlands were recruited by phone and letter. After the school's principal and fifth-grade teacher agreed to participate, parents were informed and asked for their consent for their child's participation. Data were collected from September to December (T1), January to March (T2), and April to June (T3) of the 2012-2013 school year. T1 started at least 1 month after the beginning of the school year. Measurement moments were 13-15 weeks (T1-T2) and 9-11 weeks (T2-T3) apart. At the 3 time points, students completed the questionnaires on netbook computers in the classroom. Standard instructions were given concerning voluntary participation and confidential data handling. In addition, $2 \mathrm{~h}$ of video were recorded on the same day the questionnaires were completed. During the observation, teachers followed their normal lesson plans, except for tests (because little interaction takes place during tests) and for individual student presentations (because classroom interactions then typically revolve around the presenting student which would result in unrepresentative high frequency of teacher behavior with the presenter). Teachers knew that the overall focus of the study was on the classroom climate, but were not informed regarding the specific behavior that was coded. Moreover, they were unaware of who, according to our approach, the socially marginal students were. A camera was located in the back of the classroom. To minimize intrusiveness, researchers were not in the classroom during the recordings. After T3, teachers received a summary of the findings for their classroom.

\section{Analyses}

Before performing the analyses to answer the research question, we examined the descriptive statistics, including correlations among the study variables. Spearman correlations were used, because the social marginality facets, peer disliking, and peerperceived frequency of teacher-student interaction deviated from normality.

\section{RQ1: Teacher Behavior With Students in the Social Margins of Their Classroom Group}

First, to explore if teachers treated students in the social margins of their classroom group differently from non-marginal students, we conducted a set of multilevel analyses, first for the composite score and second per facet of social marginality separately. We predicted observed and peer-perceived teacher behavior from social marginality status (non-marginal or marginal) on the entire sample. These analyses were performed for the three measurement moments together, using the SPSS (version 24) mixed procedure. Data were hierarchically nested, with teacher behavior (frequency and valence) at a single occasion and toward a single student as the lowest level (L1). Occasions were nested within students at level 2 (L2), and students were nested within classes at level 3 (L3). However, next to the class, student, and occasion level variance, for the observed teacher behavior toward a single student at a certain occasion, we needed to take into account the level of the observed teacher behavior in the class at each occasion (class*occasion; here referred to as the observed lesson-although in practice multiple consecutive lessons by the same teacher were videotaped). That is, part of the variation in frequency of teacher behavior toward a single student at a single occasion (L1) was due to characteristics of the observed lessons during the period in which the camera was recording at a certain occasion (e.g., whether we mainly recorded a teacherled classroom interaction vs. seat work). We accounted for this cross-classified nesting by modeling measurement occasions of teacher behavior with a student (L1) as being nested within 
students (L2a) as well as within lessons (L2b), which were both nested within classes (L3). This cross-classified structure is illustrated in Figure 1.

The second step was to further understand variation in teacher behavior within the group of students in the social margins of their classroom group. For the composite score and per facet separately, we regressed frequency and valence in teacher behavior, as observed and as perceived by students, on students' severity of marginalization, their peer rejection, and inclusion goals. We used multilevel process analysis (with the same levels as indicated above, again using SPSS Mixed) to predict teacher behavior at the student level (L2a; averaged over time) and at the level of the time point [L1; students' momentary deviation from their average; see Papp (2004)].

\section{RQ2: Change in Social Marginality Over Time}

To answer the second research question, a latent growth curve model was estimated in which students' slope in social marginality was regressed on teacher behavior. This model was tested only for students who were in the socially marginal subsamples at $\mathrm{T} 1$. The growth models were estimated for the compound score and per facet of social marginality.

For the composite score of social marginality, we started by testing for measurement invariance before we conducted the growth curve models, to ensure that the same latent variable was assessed at each time point (Ferrer et al., 2008). We compared a freely estimated configural model to a constrained model in which first factor loadings and next also intercepts were fixed to be equal over time. Models were compared using the SatorraBentler scaled chi-square test for nested models (Satorra, 2000). The configural model showed good fit, $\chi^{2}(15)=13.35, p=$ 0.576 ; $\mathrm{RMSEA}=0.00$; $\mathrm{CFI}=1.00$; $\mathrm{TLI}=1.00$; $\mathrm{SRMR}=0.02$. Imposing constraints on the factor loadings and intercepts did not decrease model fit: factor loadings $\Delta \mathrm{SBS}^{2}(4)=5.70, p=$ 0.223 ; intercept $\Delta \mathrm{SBS}_{\chi}{ }^{2}(6)=7.48, p=0.279$; factor loadings and intercept $\Delta S B S \chi^{2}(10)=13.28, p=0.208$.

In the first model, we tested initial growth models that only included an intercept and slope (M0). Time scores for the growth slope factor were corrected for unequal distances between T1 and $\mathrm{T} 2$ and between T2 and T3. Next, we regressed the slope of social marginality on the teacher behavior variables at T1 (M1). Then, we tested the interactions of the teacher behavior variables with rejection and inclusion goals at $\mathrm{T} 1$, to examine whether teacher behavior differentially affected changes in marginality depending on these variables (M2). The Complex function in Mplus was used to account for the nesting of the data (students within classes). Student-level predictor variables were groupmean centered before selecting the socially marginal sub-samples [see Hox (2010)].

The analyses for the compound score were set up as secondorder models [see Ferrer et al. (2008)] in Mplus version 7.4 (Muthén and Muthén, 1998-2015). Figure 2 shows the model that was fitted for M1. In second-order models, the observed variables (here: the peer nomination items of each facet) are used as indicators of a latent variable (first-order factor, here: social marginality) at each measurement occasion. Then, intercept and slope are introduced as second-order factors in M0. Finally, predictors can be added to explain variance in slope across students (M1 and M2).

\section{RESULTS}

\section{Descriptive Statistics}

Table 1 shows the means, standard deviations, range, and correlations for the variables, for the total sample (below the diagonal) and for the students in the social margins of their classroom group (based on the compound score; above the diagonal). Values represent the data prior to centering, and the nesting was not taken into account here. As expected, general social marginality correlated positively but moderately with rejection $\left(r_{s}=0.29, p<0.001\right.$; for the three facets range in $r_{\mathrm{s}}$ from 0.27 to 0.32 ), confirming that the two reflect different aspects of low peer status. Within the group of students in the social margins of their classrooms, these correlation was stronger (compound $r_{\mathrm{s}}=0.43, p<0.001$; for the three indicators range in $r_{\mathrm{s}}$ from 0.27 to 0.38 ), showing that students who were more strongly socially marginalized were also more likely to be rejected. The correlations of peer perceptions of frequency with observed frequency $\left(r_{\mathrm{s}}=0.04 / 0.15\right)$ and peer perceptions of valence with observed teacher behavior $\left(r_{\mathrm{s}}\right.$ $0.25 / 0.22$ and $-0.02 /-0.01)$ for affective and cognitive valence) were at best weak.

\section{RQ1: Teacher Behavior With Students in the Social Margins of Their Classroom Group}

First, we compared the frequency and valence of observed and peer-perceived teacher behavior between socially marginal and non-marginal students (see Table 2). Teachers interacted less frequently with socially marginal students than with other students, $F(1,815.69)=5.58, p=0.018$, particularly in the case of unpopular students, $F(1,812.80)=9.56, p=0.002$. Peers thought that students in the social margins received less teacher attention than their other classmates, $F(1,814.54)=176.11, p<$ 0.001 , which was the case for all facets of social marginalization. There was no difference for the valence of observed teacher behavior in the affective domain, $F(1,767.54)=0.36, p=0.552$, or the cognitive domain, $F(1,758.71)=0.30, p=0.586$. Also peers generally did not see a difference in the valence of teacher behavior, $F(1,809.68)=1.00, p=0.318$. However, for students whom they thought did not belong to a group they saw less positive teacher interaction than for their other classmates, $F$ ( 1 , $813.49)=10.17, p=0.001$.

\section{Variability in Teacher Behavior Within Socially Marginal Students}

Next, we delved deeper into teacher behavior with socially marginalized students. To this end we examined, within the several subsamples of students in the social margins of their classroom group and across the three time points, whether observed teacher behavior was associated with students' severity of social marginality, their peer rejection and their reported inclusion goals. 


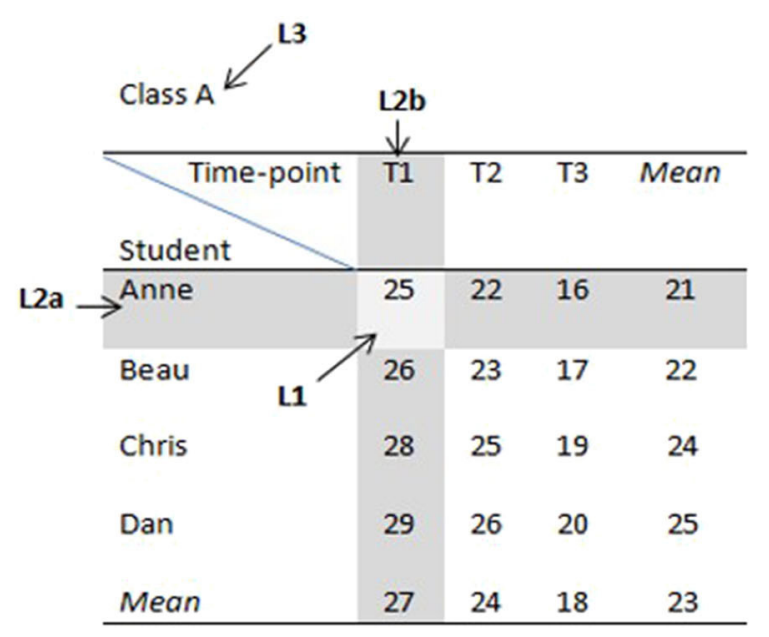

Class B

\begin{tabular}{lcccc}
\hline Time-point & T1 & T2 & T3 & Mean \\
Student & & & & \\
\hline Evelyn & 10 & 4 & 10 & 8 \\
Fred & 11 & 5 & 11 & 9 \\
George & 13 & 7 & 13 & 11 \\
Holly & 14 & 8 & 14 & 12 \\
Mean & 12 & 6 & 12 & 10 \\
\hline
\end{tabular}

FIGURE 1 | Illustration of the cross-classified data structure. Numbers represent frequency of teacher behavior with each student at each time point. Anne's score of 25 at T1 has four sources of variation: class-level variation (this is a class with a relatively high frequency; L3), student-level variation (within her class, Anne receives relatively limited teacher attention; L2a), lesson-level variation (at T1 we videotaped a lesson with a particularly high frequency of teacher behavior; L2b), and finally residual variance at L1, which is Anne's own deviation from the class' mean score, her own mean score over time, and the lesson's mean score.

A null model for teacher behavior was run first that contained only random intercepts at the within-student (L1), betweenstudent (L2a), between-lesson (L2b), and between-class (L3) levels, to see how variance in teacher behavior with socially marginal students was partitioned across these levels (see Table 3). Generally, most of the variance was located at the residual level of the measurement occasion. Frequency was most clearly different across students $(29.8 \%$ of the variance located at the student-level). For affective and cognitive valence, hardly any variance was located at the student level (3.3 and $2.6 \%$, respectively).

Next, to understand how teacher behavior could be explained by student characteristics, we regressed teacher behavior on students' severity of social marginality, peer rejection, and inclusion goals (see Table 4 for analyses with the composite score and Appendix A for results for each facet separately). The more severely students were marginalized across the three time points together, the less frequent interaction teachers had with them. This was particularly the case for unpopular students. For socially marginalized students who did not belong to a group of friends, being even more severely marginalized at a certain moment in time was associated with higher frequency of teacher interaction. When students were more severely marginalized at a specific occasion compared to their overall average, concurrent teacher behavior with them was more positive in cognitive valence, although this result was not shown in the analyses per facet and the predictors explained little variance in momentary deviations in teacher behavior.

The more students were rejected by their peers, the more frequently the teacher interacted with them, but this behavior was more negative in affective valence (between-student part of the model; all facets of social marginalization). For unpopular students, being rejected by peers was also associated with lower cognitive valence at both the between-student and the within-student level; for students who were often alone this was the case at the within-student level.

Students' inclusion goals were not associated with any of the teacher behavior variables. As was indicated above, relatively little within-student variation in teacher behavior was explained by the predictors. Student characteristics, and most importantly peer rejection, did explain 13 and $16 \%$ of the between-student variability in frequency and cognitive valence between students, and even $88 \%$ of the between-student variability in affective valence.

\section{RQ2: Change in Social Marginality Over Time}

To answer the second research question, we tested whether, within the socially marginal subsamples, observed and peerperceived teacher behavior predicted changes in the severity of students' social marginalization over time.

After the factor structure was established for the compound score, we proceeded to build the intercept and slope on this factor structure (M0, see Figure 2). This model showed a small negative slope in the overall severity of students' social marginalization, $b=-0.05, S E=0.02, p=0.006$, so on average these students became slightly less socially marginal over time. Significant slope variance, $s=0.08, S E=0.02, p=0.001$, indicated that students differed in their change in social marginality over time. This change was not associated with their initial level of social marginalization, $r=-0.01, S E=0.03, p=0.852$. Results per indicator of social marginalization showed similar patterns across all facets, with the only exception that unpopularity stayed stable instead of having a negative slope, $b=0.01, S E=0.01, p=0.339$.

In the next model (M1) we predicted the slope in severity of social marginalization from observed and peer-perceived teacher behavior in general and per facet of social marginalization (see Table 5 for the composite score and Appendix B for the 


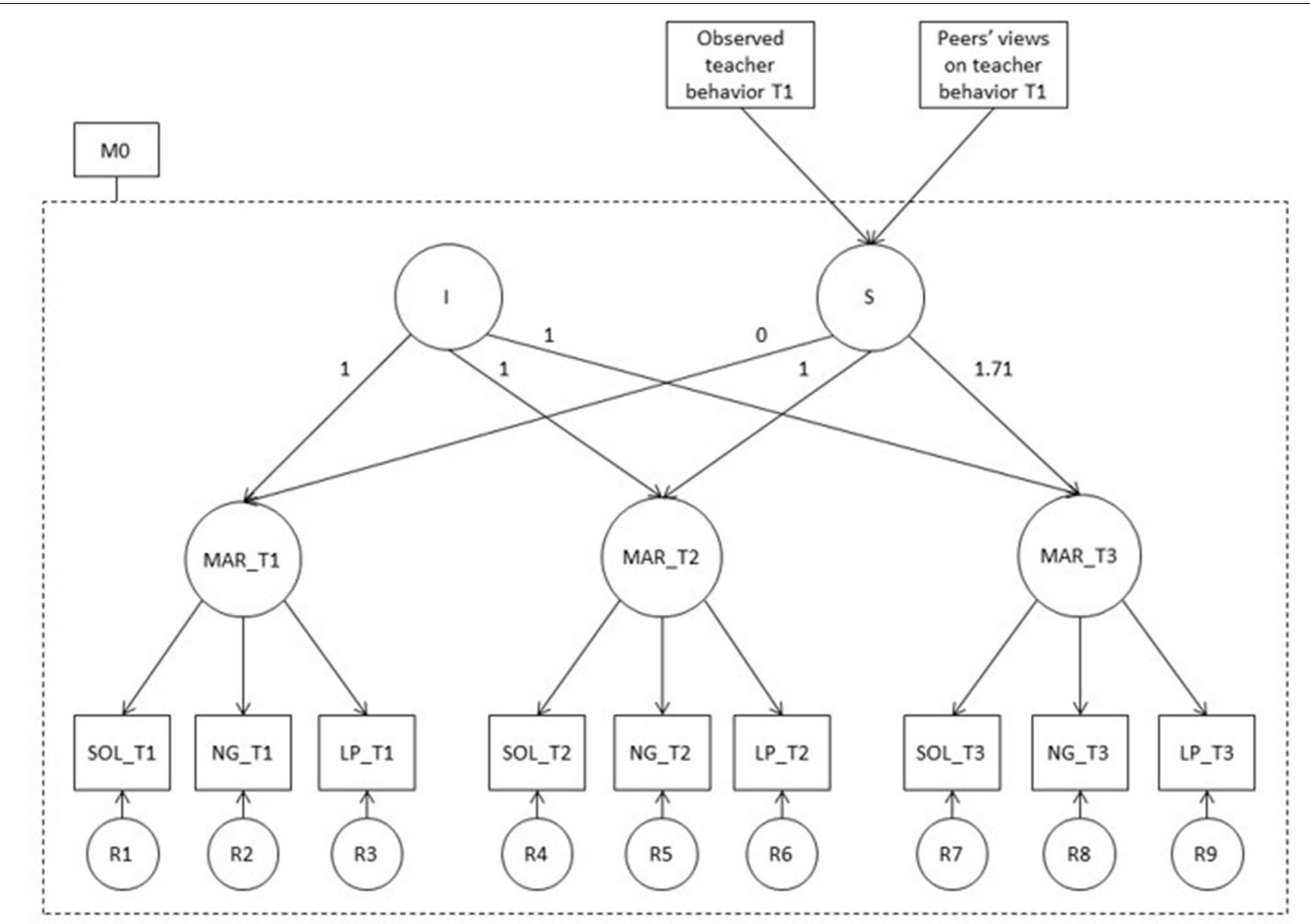

FIGURE 2 | The second-order latent growth model MI (with MO containing only the growth model indicated in dashed lines). R1 to R9 are residuals. SOL_T1 to SOL T3, solitude measured at T1 to T3. NG T1 to NG T3, not belonging to a group of friends at T1 to T3. LP T1 to LP T3, least popular at T1 to T3. MAR T1 to MAR T3, the first-order latent variable marginality at T1 to T3. I, Intercept; S, Slope (second order latent variables). The slope was regressed on observed teacher behavior as well as peer-perceived teacher behavior.

TABLE 1 | Means, standard deviations, range, and spearman correlations of study variables for the entire sample and the marginal sub-sample.

\begin{tabular}{|c|c|c|c|c|c|c|c|c|c|c|c|c|c|c|c|}
\hline & M & SD & Min & $\operatorname{Max}$ & 1 & 2 & 3 & 4 & 5 & 6 & 7 & 8 & 9 & 10 & 11 \\
\hline 1 Solitude & 0.06 & 0.12 & 0.00 & 1.00 & - & $0.46^{\star \star}$ & $0.51^{\star \star}$ & $0.83^{\star *}$ & $0.27^{\star \star}$ & $0.22^{\star \star}$ & -0.04 & -0.07 & -0.04 & $-0.20^{\star \star}$ & -0.01 \\
\hline 2 Not belonging to group & 0.08 & 0.10 & 0.00 & 0.70 & $0.44^{\star \star}$ & - & $0.38^{\star \star}$ & $0.72^{\star \star}$ & $0.38^{\star \star}$ & $0.27^{\star \star}$ & $0.13^{\star \star}$ & $-0.10^{*}$ & -0.01 & $-0.15^{\star \star}$ & $-0.20^{\star *}$ \\
\hline 4 Social marginality & 0.00 & 0.90 & -1.24 & 5.39 & $0.63^{\star \star}$ & $0.64^{\star \star}$ & $0.81^{\star \star}$ & - & $0.43^{\star \star}$ & $0.25^{\star \star}$ & -0.01 & $-0.10^{*}$ & -0.04 & $-0.24^{\star \star}$ & $-0.11^{\star *}$ \\
\hline 5 Rejection & 0.11 & 0.14 & 0.00 & 0.86 & $0.27^{\star \star}$ & $0.30^{\star \star}$ & $0.32^{\star *}$ & $-0.29^{\star \star}$ & - & $0.26^{\star \star}$ & 0.08 & $-0.17^{\star \star}$ & -0.05 & -0.06 & $-0.50^{\star \star}$ \\
\hline $8 T$ valence aff. & -0.03 & 0.28 & -1.00 & 1.00 & -0.03 & -0.02 & 0.00 & $-0.01^{\star *}$ & $-0.14^{\star \star}$ & $-0.05^{\star}$ & $-0.05^{\star \star}$ & - & $0.12^{\star \star}$ & 0.02 & $0.22^{\star \star}$ \\
\hline $9 T$ valence cogn. & 0.12 & 0.19 & -1.00 & 1.00 & 0.02 & -0.00 & -0.03 & $-0.03^{\star \star}$ & $-0.01^{\star *}$ & $-0.04^{\star *}$ & $-0.25^{\star \star}$ & $-0.08^{\star \star}$ & - & 0.03 & -0.01 \\
\hline $10 P$ frequency & 0.90 & 0.09 & 0.38 & 1.00 & $-0.26^{\star \star}$ & $-0.28^{\star \star}$ & $-0.32^{\star \star}$ & $-0.30^{\star *}$ & $-0.18^{\star \star}$ & $-0.11^{\star \star}$ & $-0.04^{*}$ & $-0.07^{\star \star}$ & $0.01^{\star *}$ & - & -0.02 \\
\hline $11 P$ valence & 0.23 & 0.31 & -0.90 & 0.94 & -0.02 & $-0.07^{\star \star}$ & $0.11^{\star \star}$ & $-0.02^{\star \star}$ & $-0.42^{\star \star}$ & $-0.07^{\star \star}$ & $-0.24^{\star \star}$ & $-0.25^{\star \star}$ & $-0.02^{\star}$ & $0.10^{\star \star}$ & - \\
\hline
\end{tabular}

T, teacher; Aff, affective; Cogn, cognitive; P, peer. Correlations below the diagonal represent correlations for the entire sample; correlations above the diagonal represent those for the socially marginal sub-sample (based on the compound score). ${ }^{*} p<0.05,{ }^{* *} p<0.01$.

separate facets). Unexpectedly, none of the teacher behavior variables was associated with students' slope of the severity of social marginalization.
Finally, we examined whether change in social position of students occupying a socially marginal position in the classroom peer group was differently associated with teacher behavior, when 
TABLE 2 | Observed and peer-perceived teacher behavior with socially marginal students and others.

\begin{tabular}{|c|c|c|c|c|c|c|c|c|}
\hline & \multicolumn{2}{|c|}{ Compound score } & \multicolumn{6}{|c|}{ Facets of social marginality } \\
\hline & $\begin{array}{c}\text { Not socially } \\
\text { marginal }\end{array}$ & $\begin{array}{l}\text { Socially } \\
\text { marginal }\end{array}$ & Not alone & Often alone & Does belong & Does not belong & Not unpopular & Unpopular \\
\hline & $M(S E)$ & $M(S E)$ & $M(S E)$ & $M(S E)$ & $M(S E)$ & $M(S E)$ & $M(S E)$ & $M(S E)$ \\
\hline \multicolumn{9}{|c|}{ Observed teacher behavior } \\
\hline Affective valence & $-0.03(0.02)$ & $-0.04(0.02)$ & $-0.03(0.02)$ & $-0.03(0.02)$ & $-0.03(0.02)$ & $-0.05(0.02)$ & $-0.03(0.02)$ & $-0.04(0.02)$ \\
\hline Cognitive valence & $0.12(0.01)$ & $0.12(0.01)$ & $0.12(0.01)$ & $0.12(0.01)$ & $0.12(0.01)$ & $0.11(0.01)$ & $0.12(0.01)$ & $0.11(0.01)$ \\
\hline \multicolumn{9}{|c|}{ Peer perceived teacher behavior } \\
\hline Frequency & $0.92(0.00)$ & $0.85(0.01)^{\star \star}$ & $0.92(0.01)$ & $0.86(0.01)^{\star \star}$ & $0.92(0.01)$ & $0.87(0.01)^{\star \star}$ & $0.92(0.00)$ & $0.85(0.01)^{\star \star}$ \\
\hline Valence & $0.23(0.02)$ & $0.21(0.03)$ & $0.23(0.02)$ & $0.22(0.02)$ & $0.25(0.02)$ & $0.18(0.02)^{\star \star}$ & $0.22(0.02)$ & $0.24(0.03)$ \\
\hline
\end{tabular}

Values are estimated means with standard errors over the 3 time points.

*Value significantly different from non-marginal students with $p<0.05$.

**Value significantly different from non-marginal students with $p<0.01$.

TABLE 3 | Variance decomposition of observed teacher behavior for socially marginal students.

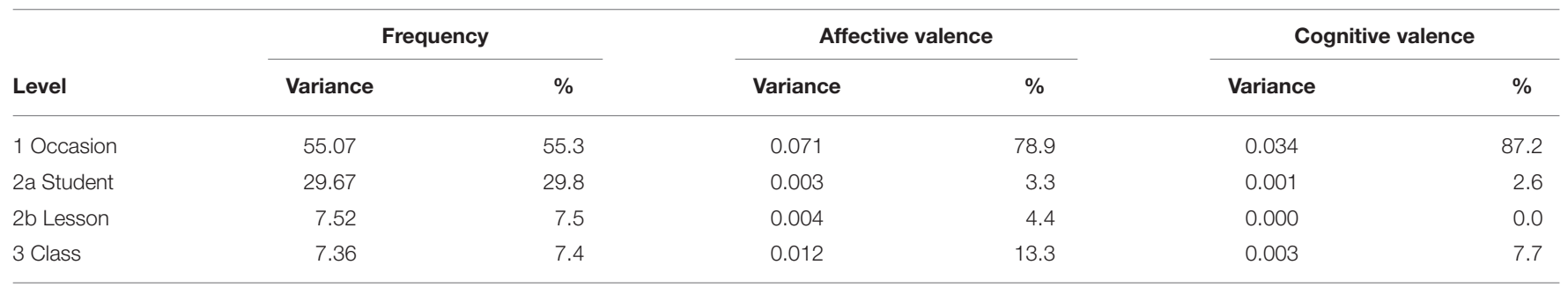

This table is based on the socially marginal subsample only, using the compound score of social marginality.

TABLE 4 | Results of the multilevel analyses predicting frequency and valence in observed teacher behavior with socially marginal students.

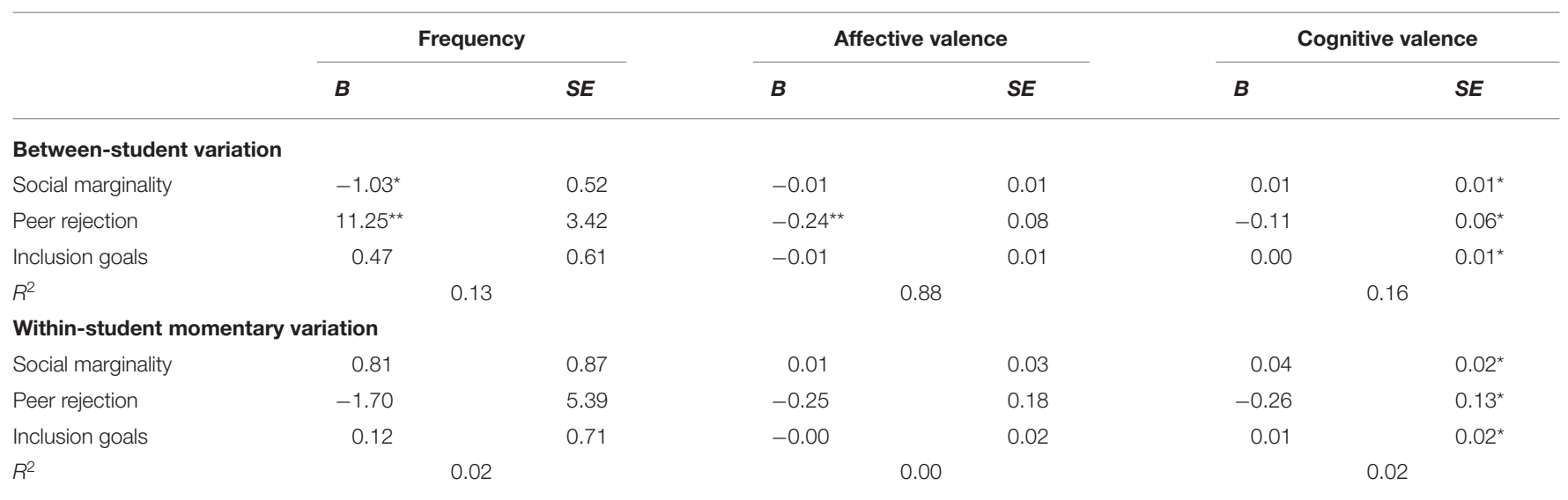

This table is based on the social marginality composite score. Results for each facet separately can be found in Appendix A.

${ }^{*} p<.05,{ }^{* *} p<.01$.

they were (a) more rejected or (b) had stronger inclusion goals (M2). Only the interaction of observed valence in the cognitive domain with peer rejection was significant. Figure 3 shows how teacher cognitive valence was related to the slope in marginality for students high and low $(+/-1 S D)$ in peer rejection. It appeared that for more strongly rejected students, more positive teacher behavior affected social integration, as it predicted a more negative slope in the severity of social marginalization. This was the case for both solitude (particularly cognitive valence) and not belonging to a group (affective valence), but not for unpopularity. 
TABLE 5 | Results of the growth curve model predicting the slope of social marginality.

\begin{tabular}{|c|c|c|c|c|}
\hline & \multicolumn{2}{|l|}{ M1 } & \multicolumn{2}{|l|}{ M2 } \\
\hline & $B(S E)$ & $\beta$ & $B(S E)$ & $\beta$ \\
\hline \multicolumn{5}{|l|}{ Main effects } \\
\hline Observed frequency & $-0.00(0.00)$ & -0.08 & $-0.00(0.01)$ & -0.08 \\
\hline Observed affective valence & $-0.05(0.09)$ & -0.06 & $0.05(0.31)$ & 0.07 \\
\hline Observed cognitive valence & $0.01(0.00)$ & 0.01 & $-0.15(0.37)$ & -0.11 \\
\hline Peer-perceived frequency & $0.13(0.29)$ & 0.05 & $-0.17(1.01)$ & -0.07 \\
\hline Peer-perceived valence & $-0.11(0.10)$ & -0.12 & $-0.06(0.43)$ & -0.07 \\
\hline Peer rejection & & & $0.35(0.27)$ & 0.22 \\
\hline Inclusion goals & & & $0.03(0.02)$ & 0.12 \\
\hline \multicolumn{5}{|l|}{ Interaction with rejection } \\
\hline Observed frequency & & & $-0.00(0.02)$ & -0.00 \\
\hline Observed affective valence & & & $-0.88(0.55)$ & -0.15 \\
\hline Observed cognitive valence & & & $-2.55(1.04)^{*}$ & -0.29 \\
\hline Peer-perceived frequency & & & $0.77(2.34)$ & 0.06 \\
\hline Peer-perceived valence & & & $0.00(0.02)$ & 0.09 \\
\hline \multicolumn{5}{|c|}{ Interaction with inclusion goals } \\
\hline Observed frequency & & & $0.00(0.00)$ & 0.04 \\
\hline Observed affective valence & & & $-0.01(0.09)$ & -0.03 \\
\hline Observed cognitive valence & & & $0.11(0.14)$ & 0.27 \\
\hline Peer-perceived frequency & & & $0.08(0.34)$ & 0.11 \\
\hline Peer-perceived valence & & & $0.03(0.12)$ & 0.11 \\
\hline$R^{2}$ slope & 0.02 & & 0.14 & \\
\hline
\end{tabular}

This table is based on the social marginality composite score. Results for each facet separately can be found in Appendix B. ${ }^{*} p<0.05$.

\section{DISCUSSION}

As socially marginalized students are at risk for adjustment problems, it is important for teachers to find ways to foster their social participation. In the present study, we examined if a teacher social referencing mechanism applies to students' social marginality. Based on research testing social referencing theory (Hughes et al., 2001, 2014; McAuliffe et al., 2009; Hendrickx et al., 2017b), we expected a modeling effect of frequency and valence in teacher behavior, so that students would become less severely socially marginalized over time. On average, teachers however interacted less frequently with these students, thereby potentially perpetuating students' socially marginal position rather than alleviating it. This was particularly true for students who were considered unpopular by their peers. Further, frequency of teacher interaction as such was not associated with a change in the severity of social marginalization over time. Overall the link between the nature of teacher behavior and the severity of students' social marginalization was weak. However, differential effects were found for students who were also rejected by their peers. Positive valence in observed teacher behavior was associated with becoming less severely socially marginalized over time, only when students were also peer rejected. Thus, specifically socially marginal students that were also rejected seemed to benefit from positive teacher behavior. Overall, there

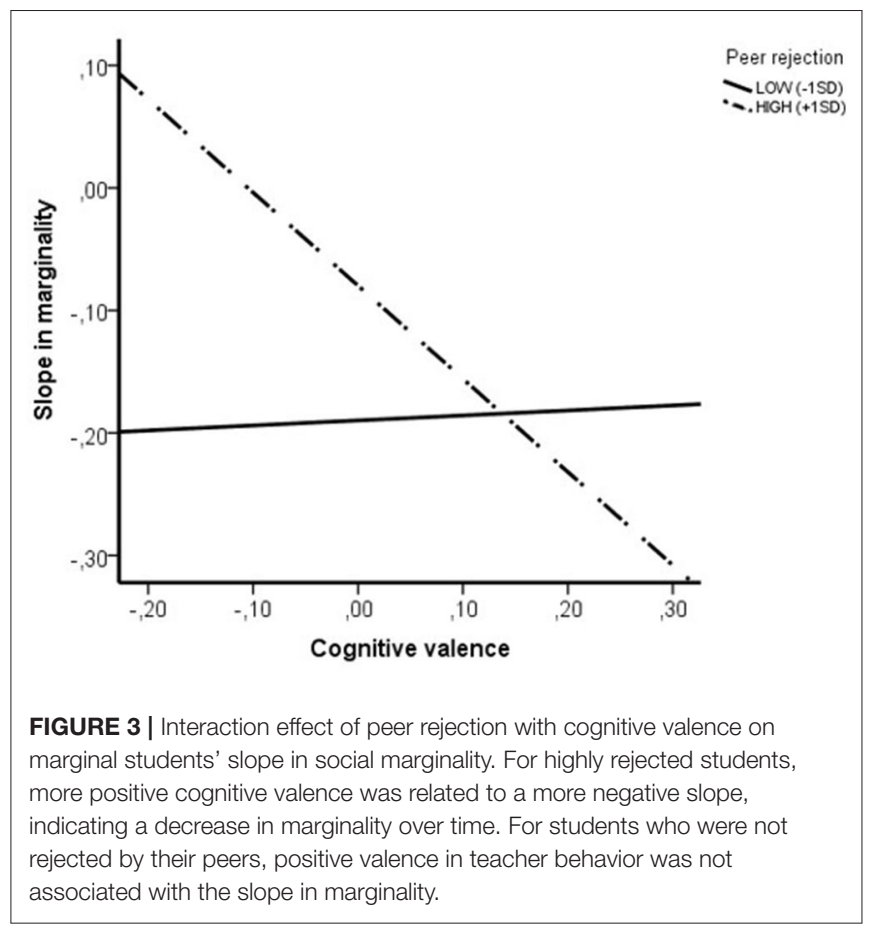

was no clear pattern in the effects of interactions within the cognitive and the affective domains. Socially marginal students that were also rejected had more negative interactions in the affective domain, but more positive interactions in the cognitive domain predicted less severe social marginalization over time.

\section{Teacher Behavior With Socially Marginalized Students}

In line with findings in preschool groups (Evans, 2001; Rudasill and Rimm-Kaufman, 2009), teachers interacted less frequently with students in the social margins of their classroom group than with their classmates, particularly if these students were considered unpopular. Thus, in terms of frequency, teachers acted in accordance with students' limited social participation. These students' social marginality and limited social impact may have resulted in them not standing out much in the group and therefore not attracting much teacher attention and this effect was even stronger as students were considered less popular. Classmates also more often indicated the socially marginalized students as those who received less teacher attention, which was the case for all three facets of social marginalization. Overall, although interaction frequency was lower, there was no marked difference in the valence of interactions in the cognitive and affective domains with socially marginalized students.

These findings indicate that although we assumed teacher behavior to affect social marginality, the direction of this association might also be the other way around: students' social position affects teacher behavior. This conclusion is worrisome, as by structurally having less frequent interaction with students in the margins of the classroom peer group, teachers might send the message to the rest of the classroom that it is normal to 
ignore them and leave them out of social interaction. Thereby, teachers may unintentionally maintain the socially marginal position of these students. Only for socially marginalized students who did not belong to a group of friends, being even more severely marginalized at a certain moment in time was associated with higher frequency of teacher interaction. This finding might indicate the teachers' effort to include these students in the classroom peer group.

Rejection was an important factor in the dynamic of social marginalization and teacher behavior. When socially marginalized students were more rejected by their peers, the frequency of teacher interaction was higher but also more negative, specifically in the affective domain. The tendency to have more conflicted interactions with more rejected students is again in line with the socially marginal position of students, rather than counteracting this tendency. Students who are rejected by their peers often show behaviors that can be considered undesirable, such as aggression (Asher and McDonald, 2009). Although some negativity may be necessary to tackle students' undesirable behavior for classroom management purposes, investing in positive interaction with a rejected student, and according to our results specifically in the cognitive domain, may in the long run positively affect classmates' social inclusion of this student. This, in turn, could decrease this student's undesirable behavior (Ladd, 2006). In this way, the teacher might be able to break the negative cycle of rejection negative responses.

\section{The Teacher as a Social Referent for Social Marginalization}

There were no overall effects of teacher behavior on changes in the severity of students' social marginality or any of its facets over the course of a school year. This may partly be explained by the non-adaptive behavior teachers generally displayed toward marginal students. Few examples of with regard to social marginalization non-congruous teacher behavior (i.e., frequent and positive interaction) were present in the data, confining the possibilities to find evidence for social referencing processes that support social integration.

The small role of the teacher in changes in social marginalization is possibly also rooted in the relational history most classes had as a group. In Dutch primary schools, students generally have a new teacher every year, whereas the peer group stays mostly the same. Thus, in order for the teacher to affect the social integration of socially marginalized students, counterbalancing typical peer interactions might not be enough to eliminate years of peer experiences and reputations. Accordingly, teacher behavior may need to be much more pronounced than the naturally occurring behavior observed in the current sample.

\section{Social Referencing and Social Marginality of Rejected Students}

For socially marginalized students who were more strongly rejected by their peers, positive teacher behavior was related to more social integration over time. Rejected students in particular seemed to benefit from being treated more positively, reflecting the earlier findings from the perspective of social referencing theory (Hughes et al., 2001, 2014; Hendrickx et al., 2017b), that more positive valence in teacher behavior is associated with lower levels of peer rejection. These effects were found for students who were often alone and students who did not belong to a group of friends, and both for cognitive valence (compound score and solitude) and affective valence (not belonging to a group of friends). Why should in particular peer rejection be related to teacher behavior? This may be because feelings of (active) dislike peers have for a student may be relatively salient, and any positive teacher behavior with a disliked student may therefore be more salient or contrasting than positive behavior with a classmate they do not engage with much. That is, students may generally have less strong feelings about a classmate who does not belong to the group but is not rejected. Because of the limited visibility of students in the social margins of their classroom group, there may be no sharp contrasts between feelings toward such a student and teachers' behavior. This would reflect a "double catch" for those students, as it implies that teachers' behavior with marginal students has limited power to grasp peers' attention and to subsequently function as a model.

\section{Different Facets of Social Marginalization}

The present study has focused on three facets of social marginalization, thereby providing both a general view on the concept and distinguishing facets of social marginalization specifically. In our results, unpopularity seemed to relate slightly differently to teacher behavior as compared to solitude and not belonging to a group of friends. Conceptually, (un-)popularity differs from the other two facets. That is, whereas both solitude and not belonging to a group refer to not being surrounded by many others, unpopularity is associated with not having a very high status or social impact in a group. One can be unpopular in the peer group, but still have one or two close friends (e.g., two or three neglected students who connect well to each other). This underlines the notion that social marginality is a multidimensional construct and that to understand it well, different facets need to be taken into consideration. However, not so much the different facets of social marginalization but being rejected was important regarding the dynamics of marginalization and teacher behavior. Only in connection with rejection, differential effects of the cognitive and affective domains of teacher interaction became visible.

\section{Limitations and Suggestions for Future Research}

The results of this study must be interpreted in the light of some limitations. First, our classroom observations were limited in multiple ways. That is, we only recorded $2 \mathrm{~h}$ per wave, which may have limited predictive power. As is shown in the relatively high occasion-level variance, teacher behavior was rather dependent on the observed moment. An extended observation that covered a longer period of time might be essential to find effects of teacher behavior. Moreover, we limited our measure of observed teacher behavior to verbal expressions. Non-verbal teacher behaviors, such as giving a student a thumbs-up or high five may also be important for classmates' perceptions of how the teacher interacts with and evaluates a student. Also, it may be relevant to examine 
teacher behavior outside the classroom, for instance during breaks, in the hallway or on field trips. Finally, observations were limited in the sense of only one teacher being recorded. It is likely that in those cases where there were two teachers in the classroom it was not just the teacher who participated who could have an impact on the classroom social system in general and the social position of marginal students in particular, so observations could be extended to the second teacher as well. In sum, for future research observations could be extended to a longer time period, a wider range of teacher behavior, a wider range of settings, and to both teachers when available. However, our approach already included $6 \mathrm{~h}$ of observation per class and many more hours of coding, so extending observations might be a big challenge.

A second limitation was that in the current study, we did not include student behavior, which is a potentially important factor in both students' social marginalization and teacher behavior. For instance, acting aggressively is known to hinder both positive relations with peers and positive interactions with teachers. For future research it would be interesting to incorporate student behavior as a predictor of students' marginality as well as teacher behavior. Possibly, teacher behavior has differential effects for students' social position in the classroom peer group (Hendrickx et al., 2017a).

A possible explanation for our findings might be that naturally occurring teacher behavior was not salient or frequent enough to improve marginal students' social integration. Future research might benefit from systematically manipulating teacher behavior, in order to increase this variability and thereby expand the range of observed teacher behaviors. Also, in the Dutch context students stay in the same group for several years. This stability may make it hard for teachers to induce changes, particularly because the difficulty of changing a reputation once it is built. Moreover, it would be interesting to see if teacher behavior changes in correspondence with more social integration. Based on the idea that teacher behavior follows students' status, we would expect to find an effect from student marginalization on teacher behavior at a later time point. Finally, future research may benefit from examining teachers' accuracy in their judgment of students' peer relations (Hamm and Hoffman, 2016), which may facilitate teachers' adaptive behavior (Hoffman et al., 2015). If teachers are unaware of who the students in the social margins of the group are, they cannot be expected to purposefully intervene or change their practices accordingly. In general, however, teacher judgments of peer relationships seem to have limited overlap with peer reports [see Gest (2006), Hoffman et al. (2015), Neal et al. (2011)].

\section{Practical Implications}

The study findings provide some practical implications for teachers. Teachers seemed largely to behave in accordance with students' socially marginal position in the classroom group: they had infrequent interactions with them. As was stated in section 4.4, it is important for teachers to be attuned to their students' social status in general, and social marginalization in particular, so they can act upon this information to increase students' social integration. Students in the social margins of the group who also were rejected seemed to benefit from receiving positive teacher comments, particularly in the cognitive domain. Therefore, the clearest indication of this study for teachers is to avoid negativity and increase positivity in public interactions with students that are socially marginalized, particularly with students who are also peer rejected. Intervention studies aimed at increasing the valence of teacher behavior with students in general (Mikami et al., 2011) and with students with externalizing behaviors in particular (Spilt et al., 2012) have shown positive effects on teacher behavior and peer relations. Such findings are promising for the possible success of intervention programs aimed at social marginalization.

\section{DATA AVAILABILITY STATEMENT}

The raw data supporting the conclusions of this article will be made available by the authors, without undue reservation.

\section{ETHICS STATEMENT}

Ethical review and approval was not required for the study on human participants in accordance with the local legislation and institutional requirements. Written informed consent to participate in this study was provided by the participants' legal guardian/next of kin.

\section{AUTHOR CONTRIBUTIONS}

$\mathrm{MH}, \mathrm{TM}, \mathrm{AC}$, and $\mathrm{MB}$ designed the study. $\mathrm{MH}$ performed data collection. $\mathrm{MH}, \mathrm{TM}, \mathrm{AC}$, and $\mathrm{MB}$ performed the statistical analyses. $\mathrm{MH}$ wrote the manuscript in close collaboration with TM, while AC and MB provided feedback. All authors contributed to the article and approved the submitted version.

\section{FUNDING}

This research was supported by a grant from the Netherlands Organization for Scientific Research (NWO; 411-10-915).

\section{SUPPLEMENTARY MATERIAL}

The Supplementary Material for this article can be found online at: https://www.frontiersin.org/articles/10.3389/feduc. 2020.568849/full\#supplementary-material

\section{REFERENCES}

Arbeau, K. A., Coplan, R. J., and Weeks, M. (2010). Shyness, teacherchild relationships, and socio-emotional adjustment in grade
1. Int. J. Behav. Dev. 34, 259-269. doi: 10.1177/01650254093 50959

Asher, S. R., and McDonald, K. L. (2009). "The behavioral basis of acceptance, rejection, and perceived popularity," in Handbook of Peer Interactions, 
Relationships, and Groups, eds. K. H. Rubin, W. M. Bukowski, and B. Laursen (New York, NY: Guilford), 232-248.

Author et al. (2016).

Borgatti, S. P., Everett, M. G., and Johnson, J. C. (2013). Analyzing Social Networks. London: SAGE Publications.

Bukowski, W. M., and Véronneau, M.-H. (2014). "Studying withdrawal and isolation in the peer group: historical advances in concepts and measures," in The Handbook of Solitude: Psychological Perspectives on Social Isolation, Social Withdrawal, and Being Alone, eds. R. J. Coplan and J. C. Bowker (Sussex: John Wiley and Sons, Ltd), 14-33.

Cillessen, A. H. N., and Marks, P. E. L. (2017). Methodological choices in peer nomination research. New Dir. Child Adolesc. Dev. 2017, 21-44. doi: $10.1002 /$ cad.20206

Coplan, R. J., Arbeau, K. A., and Armer, M. (2008). Don't fret, be supportive! Maternal characteristics linking child shyness to psychosocial and school adjustment in kindergarten. J. Abnorm. Child Psychol. 36, 359-371. doi: 10.1007/s10802-007-9183-7

Coplan, R. J., and Armer, M. (2007). A “multitude of solitude:" a closer look at social withdrawal and nonsocial play in early childhood. Child Dev. Perspect. 1, 26-32. doi: 10.1111/j.1750-8606.2007.00006.x

Coplan, R. J., and Prakash, K. (2003). Spending time with teacher: characteristics of preschoolers who frequently elicit versus initiate interactions with teachers. Early Child. Res. Q. 18, 143-158. doi: 10.1016/S0885-2006(03)00009-7

Coplan, R. J., and Rubin, K. H. (2010). "Social withdrawal and shyness in childhood: history, theories, definitions and assessment," in The Development of Shyness and Social Withdrawal in Childhood and Adolescence, eds. K. H. Rubin and R. J. Coplan (New York, NY: Guilford), 3-22.

De Laet, S., Doumen, S., Vervoort, E., Colpin, H., Van Leeuwen, K., Goossens, L., et al. (2014). Transactional links between teacher-child relationship quality and perceived versus sociometric popularity: a three-wave longitudinal study. Child Dev. 85, 1647-1662. doi: 10.1111/cdev.12216

Ellemers, N., and Jetten, J. (2013). The many ways to be marginal in a group. Pers. Soc. Psychol. Rev. 17, 3-21. doi: 10.1177/1088868312453086

Evans, M. A. (2001). "Shyness in the classroom and home," in International Handbook of Social Anxiety: Concepts, Research and Interventions Relating to the Self and Shyness, eds. W. R. Crozier and L. E. Alden (Westport, CT: Wiley), 159-183.

Farmer, T. W., McAuliffe Lines, M., and Hamm, J. V. (2011). Revealing the invisible hand: the role of teachers in children's peer experiences. J. Appl. Dev. Psychol. 32, 247-256. doi: 10.1016/j.appdev.2011.04.006

Ferrer, E., Balluerka, N., and Widaman, K. F. (2008). Factorial invariance and the specification of second-order latent growth models. Methodology 4, 22-36. doi: 10.1027/1614-2241.4.1.22

Gazelle, H., and Ladd, G. W. (2003). Anxious solitude and peer exclusion: a diathesis-stress model of internalizing trajectories in childhood. Child Dev. 74, 257-278. doi: 10.1111/1467-8624.00534

Gest, S. D. (2006). Teacher reports of children's friendships and social groups: agreement with peer reports and implications for studying peer similarity. Soc. Dev. 15, 248-259. doi: 10.1111/j.1467-9507.2006.00339.x

Gest, S. D., and Rodkin, P. C. (2011). Teaching practices and elementary classroom peer ecologies. J. Appl. Dev. Psychol. 32, 288-296. doi: 10.1016/j.appdev.2011.02.004

Hamm, J. V., and Hoffman, A. S. (2016). "Teachers' influence on students" peer relationships and peer ecologies," in Handbook of Social Influences in School Contexts: Social-Emotional, Motivation, and Cognitive Outcomes, eds. K. R. Wentzel and G. B. Ramani (New York, NY: Routledge), 208-229.

Hariri, A. R., Mattay, V., Tessitore, A., Kolachana, B., Fera, F., Goldman, D., et al. (2002). Serotonin transporter genetic variation and the response of the human amygdala. Science 297, 400-403. doi: 10.1126/science.10 71829

Henderson, H. A., Fox, N. A., and Rubin, K. H. (2001). Temperamental contributions to social behavior: the moderating roles of frontal EEG asymmetry and gender. J. Am. Acad. Child Adolesc. Psychiatry 40, 68-74. doi: 10.1097/00004583-200101000-00018

Hendrickx, M. M. H. G., Mainhard, M. T., Boor-Klip, H. J., and Brekelmans, M. (2017a). Teacher liking as an affective filter for the association between student behavior and peer status. Contemp. Educ. Psychol. 49, 250-262. doi: 10.1016/j.cedpsych.2017.03.004
Hendrickx, M. M. H. G., Mainhard, M. T., Boor-Klip, H. J., Cillessen, A. H. N., and Brekelmans, M. (2016). Social dynamics in the classroom: teacher support and conflict and the peer ecology. Teach. Teach. Educ. 53, 30-40. doi: 10.1016/j.tate.2015.10.004

Hendrickx, M. M. H. G., Mainhard, M. T., Oudman, S., Boor-Klip, H. J., and Brekelmans, M. (2017b). Teacher behavior and peer liking and disliking: the teacher as a social referent for peer status. J. Educ. Psychol. 109, 546-558. doi: $10.1037 /$ edu0000157

Hoffman, A. S., Hamm, J. V., and Farmer, T. W. (2015). Teacher attunement: supporting early elementary students' social integration and status. J. Appl. Dev. Psychol. 39, 14-23. doi: 10.1016/j.appdev.2015.04.007

Hox, J. J. (2010). Multilevel Analysis: Techniques and Applications. New York, NY: Routledge.

Hughes, J. N., Cavell, T. A., and Willson, V. (2001). Further support for the developmental significance of the quality of the teacher-student relationship. J. Sch. Psychol. 39, 289-301. doi: 10.1016/S0022-4405(01)00074-7

Hughes, J. N., and Im, M. H. (2016). Teacher-student relationship and peer disliking and liking across grades 1-4. Child Dev. 87, 593-611. doi: $10.1111 /$ cdev.12477

Hughes, J. N., Im, M. H., and Wehrly, S. E. (2014). Effect of peer nominations of teacher-student support at individual and classroom levels on social and academic outcomes. J. Sch. Psychol. 52, 309-322. doi: 10.1016/j.jsp.2013.12.004

Kiuru, N., Aunola, K., Lerkkanen, M.-K., Pakarinen, E., Poskiparta, E., Ahonen, T., et al. (2015). Positive teacher and peer relations combine to predict primary school students' academic skill development. Dev. Psychol. 51, 434-446. doi: $10.1037 / \mathrm{a} 0038911$

Ladd, G. W. (2006). Peer rejction, aggressive or withdrawn behavior, and psychological maladjustment from ages 5 to 12 : an examination of four predictive models. Child Dev. 77, 822-846. doi: 10.1111/j.1467-8624.2006.00905.x

Landis, J. R., and Koch, G. G. (1977). The measurement of observer agreement for categorical data. Biometrics 33, 159-174. doi: 10.2307/2529310

Laursen, B., Bukowski, W. M., Aunola, K., and Nurmi, J.-E. (2007). Friendship moderates prospective associations between social isolation and adjustment problems in young children. Child Dev. 78, 1395-1404. doi: $10.1111 / j .1467-8624.2007 .01072 . x$

Lee, T., and Cornell, D. (2009). Concurrent validity of the olweus bully/victim questionnaire. J. Sch. Violence. 9, 56-73. doi: 10.1080/15388220903185613

McAuliffe, M. D., Hubbard, J. A., and Romano, L. J. (2009). The role of teacher cognition and behavior in children's peer relations. J. Abnorm. Child Psychol. 37, 665-677. doi: 10.1007/s10802-009-9305-5

Mikami, A. Y., Gregory, A., Allen, J. P., Pianta, R. C., and Lun, J. (2011). Effects of a teacher professional development intervention on peer relationships in secondary classrooms. Sch. Psych. Rev. 40, 367-385. doi: 10.1080/02796015.2011.12087704

Moore, C. C., Shoulberg, E. K., and Murray-Close, D. (2012). The protective role of teacher preference for at-risk children's social status. Aggress. Behav. 38, 481-493. doi: 10.1002/ab.21446

Muthén, B. O., and Muthén, L. K. (1998-2015). Mplus (version 7.4) [computer software].

Neal, J. W., Cappella, E., Wagner, C., and Atkins, M. S. (2011). Seeing eye to eye: predicting teacher-student agreement on classroom social networks. Soc. Dev. 20, 376-393. doi: 10.1111/j.1467-9507.2010.00582.x

Nelson, L. J. (2013). Going it alone: comparing subtypes of withdrawal on indices of adjustment and maladjustment in emerging adulthood. Soc. Dev. 22, 522-538. doi: 10.1111/j.1467-9507.2012.00671.x

Papp, L. M. (2004). Capturing the interplay among within- and between-person processes using multilevel modeling techniques. Appl. Prev. Psychol. 11, 115-124. doi: 10.1016/j.appsy.2004.09.002

Poulin, F., and Dishion, T. J. (2008). Methodological issues in the use of peer sociometric nominations with middle child youth. Soc. Dev. 17, 908-922. doi: 10.1111/j.1467-9507.2008.00473.x

Reinke, W. M., Splett, J. D., Robeson, E. N., and Offutt, C. A. (2009). Combining school and family interventions for the prevention and early intervention of disruptive behavior problems in children: a public health perspective. Psychol. Sch. 46, 33-43. doi: 10.1002/pits.20352

Rubin, K. H. (1982). Nonsocial play in preschoolers: necessarily evil? Child Dev. 53, 651-657. doi: 10.2307/1129376 
Rubin, K. H., Bukowski, W. M., and Bowker, J. C. (2015). "Children in peer groups," in Handbook of Child Psychology and Developmental Science, 7th edn. ed. R. M. Lerner (New York, NY: Wiley), 175-220. doi: 10.1002/9781118963418.childpsy405

Rubin, K. H., Coplan, R. J., and Bowker, J. C. (2009). Social withdrawal in childhood. Annu. Rev. Psychol. 60, 141-171. doi: 10.1146/annurev.psych.60.110707.163642

Rudasill, K. M., and Rimm-Kaufman, S. E. (2009). Teacher-child relationship quality: the roles of child temperament and teacher-child interactions. Early Child. Res. Q. 24, 107-120. doi: 10.1016/j.ecresq.2008.12.003

Satorra, A. (2000). "Scaled and adjusted restricted tests in multi-sample analysis of moment structures," in Innovations in Multivariate Statistical Analysis, eds. R. D. H. Heijmans, D. S. G. Pollock and A. Satorra (London: Kluwer Academic Publishers), 233-247.

Spangler, T., and Gazelle, H. (2009). Anxious solitude, unsociability, and peer exclusion in middle childhood: a multitrait-multimethod matrix. Soc. Dev. 18, 833-856. doi: 10.1111/j.1467-9507.2008.00517.x

Spilt, J. L., Koomen, H. M. Y., Thijs, J. T., and Van der Leij, A. (2012). Supporting teachers' relationships with disruptive children: the potential of relationship-focused reflection. Attach. Hum. Dev. 14, 305-318. doi: 10.1080/14616734.2012.672286

Statistics Netherlands (2012). Aandeel Allochtonen Per Gemeente [Percentages Immigrants by Municipality]. Retrieved from http://www.cbs.nl/nl-NL/menu/ themas/dossiers/allochtonen/cijfers/extra/aandeel-allochtonen.htm (accessed February 17, 2017).

Thijs, J. T., Koomen, H. M. Y., and van der Leij, A. (2006). Teachers' selfreported pedagogical practices toward socially inhibited, hyperactive, and average children. Psychol. Sch. 43, 635-651. doi: 10.1002/pits. 20171
Van den Berg, Y., Lansu, T. A. M., and Cillessen, A. H. N. (2020). Preference and popularity as distinct forms of status: a meta-analytic review of 20 years of research. J. Adolesc. 84, 78-95. doi: 10.1016/j.adolescence.2020. 07.010

Veerman, J. W., Straathof, M. A. E., Treffers, P. H. D. A., van den Bergh, B. R. H., and ten Brink, L. T. (2004). Competentiebelevingsschaal Voor Kinderen [SelfPerceived Competence for Children]. Amsterdam: Harcourt Test Publishers.

Wentzel, K. R. (2005). "Peer relationships, motivation, and academic performance at school." in Handbook of Competence and Motivation, eds. A. Elliot and C. Dweck (New York, NY: Guilford), 279-296.

White, K. J., and Kistner, J. (1992). The influence of teacher feedback on young children's peer preferences and perceptions. Dev. Psychol. 28, 933-940. doi: 10.1037/0012-1649.28.5.933

Wormington, S. V., Anderson, K. G., Schneider, A., Tomlinson, K. L., and Brown, S. A. (2016). Peer victimization and adolescent adjustment: does school belonging matter? J. Sch. Violence 15, 1-21. doi: 10.1080/15388220.2014.922472

Conflict of Interest: The authors declare that the research was conducted in the absence of any commercial or financial relationships that could be construed as a potential conflict of interest.

Copyright $(\odot 2020$ Hendrickx, Mainhard, Cillessen and Brekelmans. This is an openaccess article distributed under the terms of the Creative Commons Attribution License (CC BY). The use, distribution or reproduction in other forums is permitted, provided the original author(s) and the copyright owner(s) are credited and that the original publication in this journal is cited, in accordance with accepted academic practice. No use, distribution or reproduction is permitted which does not comply with these terms. 